\title{
COMPARATIVE SERUM TESTING WITH CARDIOLIPIN AND CRUDE HEART EXTRACT WASSERMANN ANTIGENS*
}

\author{
BY
}

\author{
I. N. ORPWOOD PRICE and A. E. WILKINSON
}

The Whitechapel Clinic, London Hospital

In a previous report (Price and Wilkinson, 1950) the results of parallel testing of sera with cardiolipin Wassermann antigen and the crude heart extract antigen, as used in the Harrison-Wyler Wassermann technique (Wyler, 1929), were presented. The cardiolipin antigen was found to be appreciably more sensitive than the Harrison-Wyler antigen, and in a group of " problem" sera to give fewer nonspecific reactions.

Further experiments with crude heart extract antigens showed that their sensitivity could be increased considerably by using them at a titre, individual for each extract, arrived at by the application of the principle of optimal proportions (Price, 1950a). The cholesterolized alcoholic extract used in the Harrison-Wyler technique is used at a fixed titre of 1 in 15 parts of saline, and individual batches of extract are not titrated. The examination of sera in parallel tests using this standard HarrisonWyler antigen and the same cholesterolized alcoholic extract at its optimal titre showed that the latter was considerably more sensitive and that its specificity was not appreciably different from that of the Harrison-Wyler antigen (Price and Wilkinson, 1951). It was therefore thought desirable to complete the investigation by comparing the performance

*Received for publication January 7, 1952. of cardiolipin antigen with a crude heart antigen used at its optimal titre. The results of this last series of parallel tests are presented below.

\section{Technique}

The Whitechapel Clinic Wassermann method, as described by Price (1950b) was used with both antigens. Sera were tested in parallel on the same day; when discrepant results were obtained, tests were repeated on the next day on serum freshly removed from the original specimen of blood sent to the laboratory. By this means, laboratory errors are minimized.

The cardiolipin antigen used had the composition cardiolipin 0.05 per cent., lecithin 0.05 per cent., and cholesterol 0.5 per cent.; it was used at a dilution of 1 in 400 , its optimal titre. The cholesterolized crude heart extract antigen (O.T. antigen) was used at its optimal titre of 1 in 320 .

The sera tested came from three sources :

Group $A .-1,007$ sera from patients attending the Whitechapel Clinic.

Group B.-879 sera from patients attending the

London Hospital ; 424 of them from pregnant women.

Group C. - 990 sera sent to the Venereal Diseases Reference Laboratory (Medical Research Council). Many of these were sent for confirmatory tests, but the group included many " problem" sera which had given anomalous results in other laboratories.

The sera of Groups A and B form a representative sample which might be sent for examination to any

TABLE I

RESUlTS OF PARALLEL TESTING OF SERA FROM THE WHITECHAPEL CLINIC

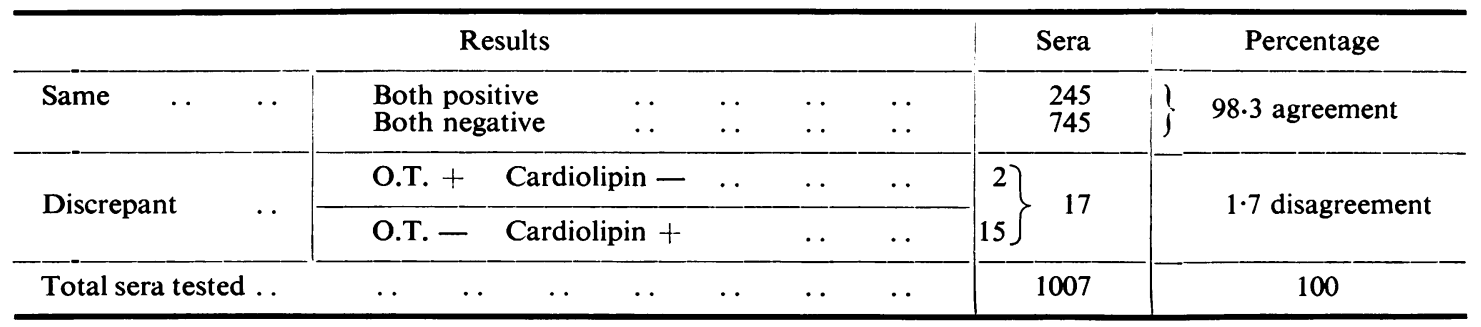


laboratory carrying out routine serum tests for syphilis. Those in Group C are, to a large extent, selected, but were included as it was hoped that they would yield information about the relative specificity of the two antigens.

\section{Results}

Group $A$.--The results are summarized in Table $\mathbf{I}$.

One of the two sera which reacted with the O.T. but not with the cardiolipin antigen came from a patient with treated syphilis and the other from a patient with prostatorrhoea with no clinical evidence of syphilis. His subsequent tests were negative and it is thought that this was a non-specific reaction, its cause being unknown.

Twelve of the fifteen sera which reacted only with the cardiolipin antigen came from patients with treated syphilis.

The histories of the other three are as follows :

(a) One serum came from a man with gonorrhoea who had no history or signs of syphilis. In 1946 he had non-gonococcal urethritis and on this occasion his serum gave anomalous reactions with the Kahn test, the Wassermann reaction being negative. As he has not attended for surveillance after treatment of his gonorrhoea it is not possible to give a definite opinion as to the specificity of these serum reactions.

(b) The second patient was a blood donor who had been found elsewhere to have a positive Wassermann reaction. There was no clinical evidence or history of syphilis, but he had had gonorrhoea, treated by eight injections of penicillin, 2 years previously. He has now been observed for 6 months and prior to the finding of a positive reaction with cardiolipin his serum reactions had been positive with the O.T. antigen on nine occasions. Price's Precipitation Reaction (P.P.R.) has been consistently negative. The cerebrospinal fluid was found to be normal. (c) The third patient giving anomalous results was a woman with chronic gonococcal salpingitis which had been treated with 4.8 mega-units of penicillin from November 30 to December 7, 1950. There was no clinical evidence or history of syphilis, but from November 29, 1950, to April 7, 1951, her serum tests showed a positive Wassermann reaction with O.T. antigen and a negative P.P.R. After the last date the Wassermann reaction became negative with O.T. antigen, but examination with cardiolipin antigen on July 9, 1951, gave a positive result.

Another specimen which was examined at the Reference Laboratory on June 18, 1951, and included in Group C, was positive with the cardiolipin antigen and with the Kahn test, but negative with the O.T. antigen and with the P.P.R. The patient denied extra-marital intercourse and it was not possible to examine her husband, who was at sea. On the evidence available it is not considered possible to be certain whether these were a series of non-specific reactions, or whether the patients did, in fact, have syphilis.

Group B.-The results of examination of sera in this group are summarized in Table II. The six sera which reacted only with cardiolipin antigen came from patients with the following diagnoses : gumma of thigh, tabes dorsalis, ? intra-cerebral thrombosis, epilepsy, and anaemia. In the remaining case, the diagnosis was not stated and there was insufficient serum to carry out confirmatory tests. Sera from the patients with epilepsy and ? intracerebral thrombosis had on previous occasions reacted with the O.T. and cardiolipin antigens.

In this group both antigens had a very similar performance, both as regards sensitivity and specificity. The group included 50 per cent. of antenatal sera which afford a good test of the qualities of an antigen. Three of these antenatal sera gave weak reactions with both antigens, the P.P.R. being negative; all these three patients were attending the Whitechapel Clinic for treatment of syphilis.

TABLE II

RESULTS OF PARALLEL TESTING OF SERA FROM THE LONDON HOSPITAL

\begin{tabular}{|c|c|c|c|c|c|c|c|c|c|}
\hline \multicolumn{8}{|c|}{ Results } & \multirow{2}{*}{$\begin{array}{r}\text { Sera } \\
36 \\
837\end{array}$} & \multirow[t]{2}{*}{ Percentage } \\
\hline Same & $\cdots$ & $\begin{array}{l}\text { Both pos } \\
\text { Both neg }\end{array}$ & $\begin{array}{l}\text { tive } \\
\text { tive }\end{array}$ & $\begin{array}{l}\cdots \\
\cdots\end{array}$ & $\begin{array}{l}\cdots \\
\cdots\end{array}$ & $\begin{array}{l}\cdots \\
\cdots\end{array}$ & $\cdots$ & & \\
\hline Discrepant & . & O.T. - & Car & $\operatorname{in}+$ & & $\cdots$ & . & 6 & 0.7 disagreement \\
\hline \multicolumn{2}{|c|}{ Total sera tested .. } & $\cdots$ & & $\cdots$ & $\cdots$ & . & $\cdots$ & 879 & 100 \\
\hline
\end{tabular}


TABLE III

RESUltS OF PARALlel TESTING OF SERA SENT TO THE REFERENCE LABORATORY

\begin{tabular}{|c|c|c|c|c|c|c|c|c|}
\hline \multicolumn{6}{|c|}{ Results } & & Sera & Percentage \\
\hline Same & $\begin{array}{l}\text { Both positive } \\
\text { Both negative }\end{array}$ & $\begin{array}{l}\ldots \\
\ldots\end{array}$ & $\begin{array}{l}\ldots \\
\ldots\end{array}$ & $\because$. & $\begin{array}{l}. . \\
.\end{array}$ & & $\begin{array}{l}591 \\
327\end{array}$ & $92 \cdot 7$ agreement \\
\hline \multirow{2}{*}{ Discrepant } & O.T. $+\mathrm{Ca}$ & in - & & .. & . & \multirow{2}{*}{\multicolumn{2}{|c|}{$\begin{array}{l}11 \\
61\end{array}$}} & \multirow{2}{*}{$7 \cdot 3$ disagreement } \\
\hline & O.T. $-\mathrm{Ca}$ & $\sin +$ & & & .. & & & \\
\hline Total sera tested .. & . & .. & . & .. & .. & & 990 & 100 \\
\hline
\end{tabular}

Group C.-The results of examination of these sera are summarized in Table III. The majority of discrepant results in this group were found with sera from cases of treated syphilis; 37 sera of this nature reacted only with the cardiolipin antigen and a further three only with the O.T. antigen. This confirms the findings with the Group A sera and indicates that cardiolipin is the more sensitive of the two antigens when the sera tested come from cases of treated syphilis.

The remaining 32 sera giving discrepant results came from patients with a miscellany of clinical diagnoses.

(a) Eight reacted only with the O.T. antigen; of these three were from pregnant women (two sera from one patient), one from a blood donor, one from a patient with trigeminal neuralgia, and two from patients with hypertension. No details were known about the remaining eighth patient.

(b) Twenty-four reacted only with the cardiolipin antigen. Nine of these came from six pregnant women, four from cases of urethritis, (two of which were gonococcal), two from patients with chronic gonococcal salpingitis (one of these is described in Group A), four from a male West African patient who had had gonorrhoea two years previously, two from a patient with secondary anaemia, and one each from patients with the diagnoses of arthrodesis of the knee, haemolytic anaemia, and glandular fever. This last serum was interesting in that after absorption with sheep cells it failed to react with cardiolipin antigen.

\section{Commentary}

The results obtained with the sera in Groups A and $\mathrm{C}$ demonstrate that cardiolipin is the more sensitive antigen when used to examine sera from cases of treated syphilis. It has not yet been possible to compare the sensitivities of these antigens with sera from a sufficient number of cases of primary syphilis to form an opinion of their relative value at this stage of the disease.

In view of the increasing application of serological testing to presumably healthy persons, such as pregnant women and blood donors, the specificity of antigens to be used in these tests becomes a matter of the utmost importance.

Among the sera from the Whitechapel Clinic patients, the O.T. antigen reacted with one serum from a patient who was thought not to have syphilis. The cardiolipin antigen reacted with the sera of three patients with no clinical evidence of syphilis, but it should be emphasized that the sera of two of these patients had also reacted with the O.T. antigen on numerous occasions before the present series of parallel tests was begun. In this group, therefore, there was little difference in the specificity of the two antigens, the incidence of possible non-specific results being between $0 \cdot 1$ and 0.3 per cent.

In the London Hospital series of sera, the O.T. antigen gave no non-specific reactions, while the cardiolipin antigen gave positive reactions with four sera from patients who were not diagnosed as syphilitic. Sera from two of these patients had reacted with the O.T. antigen on previous occasions when cardiolipin antigen was not being used in parallel ; technical error could not be ruled out in the remaining case owing to lack of serum. If this last serum be excluded from consideration, the incidence of presumed non-specific reactions with cardiolipin antigen in this group is 0.34 per cent.

Because the sera sent to the Reference Laboratory form a selected group, they cannot be used to assess the incidence of non-specific reactions with the two antigens when these are used for the testing of routine sera. Among the 32 sera from patients in whom the diagnosis of syphilis had not been made and discrepant results were obtained, the O.T. antigen gave positive reactions with eight sera from six patients, and the cardiolipin antigen 24 positive results with sera from seventeen patients. This suggests that the cardiolipin antigen, while more sensitive than the O.T. antigen when used with sera from treated cases of syphilis, may be less specific than the latter.

The incidence of $0 \cdot 3-0 \cdot 34$ per cent. non-specific results with the sera of patients in Groups A and B 
is not unduly high when the very high level of sensitivity of the cardiolipin antigen is taken into account. The O.T. antigen gave fewer non-specific results than cardiolipin in the sera of these groups, but this advantage may be partly offset by its slightly lower sensitivity in treated cases.

\section{Summary}

(1) 2,876 sera have been tested in parallel by the Whitechapel Clinic Wassermann technique using cardiolipin and crude heart extract antigens at their optimal titres.

(2) The cardiolipin antigen was found to be more sensitive than the crude heart extract antigen when used to test sera from treated syphilitic patients.
Sufficient data have not yet been collected regarding the performance of the two antigens with sera from patients with primary syphilis.

(3) The cardiolipin antigen gave more nonspecific reactions with routine sera than the crude heart extract antigen.

\section{REFERENCES}

Price, I. N. O. (1950a). British Journal of Venereal Diseases, 26, 33. (1950b). Ibid., 26, 172.

-, and Wilkinson, A. E. (1950). Lancet, 1, 14. , (1951). British Journal of Venereal Diseases, 27, 191.

Wyler, E. J. (1929). Spec. Rep. Ser. med. Res. Coun., Lond., No. 129. 